\title{
Physiological Effects of Shinrin-yoku (Taking in the Atmosphere of the Forest) in an Old-Growth Broadleaf Forest in Yamagata Prefecture, Japan
}

\author{
Yuko Tsunetsugu ${ }^{1)}$, Bum-Jin Park ${ }^{1)}$, Hideki Ishiii ${ }^{2)}$, Hideki Hirano ${ }^{3)}$, \\ Takahide Kagawa $^{1)}$ and Yoshifumi Miyazaki ${ }^{1)}$ \\ 1) Forestry and Forest Products Research Institute \\ 2) Graduate School of the University of Tokyo \\ 3) Ministry of the Environment
}

\begin{abstract}
The physiological effects of "Shinrin-yoku" (taking in the atmosphere of the forest) were examined by investigating blood pressure, pulse rate, heart rate variability (HRV), salivary cortisol concentration, and immunoglobulin A concentration in saliva. Subjective feelings of being "comfortable", "calm", and "refreshed" were also assessed by questionnaire. The subjects were 12 male university students aged from 21 to 23 (mean \pm SD: $22.0 \pm 1.0$ ). The physiological measurements were conducted six times, i.e., in the morning and evening before meals at the place of accommodation, before and after the subjects walked a predetermined course in the forest and city areas for 15 minutes, and before and after they sat still on a chair watching the scenery in the respective areas for 15 minutes. The findings were as follows. In the forest area compared to the city area, 1) blood pressure and pulse rate were significantly lower, and 2) the power of the HF component of the HRV tended to be higher and LF/(LF+HF) tended to be lower. Also, 3) salivary cortisol concentration was significantly lower in the forest area. These physiological responses suggest that sympathetic nervous activity was suppressed and parasympathetic nervous activity was enhanced in the forest area, and that "Shinrin-yoku" reduced stress levels. In the subjective evaluation, 4) "comfortable", "calm", and "refreshed" feelings were significantly higher in the forest area. The present study has, by conducting physiological investigations with subjective evaluations as supporting evidence, demonstrated the relaxing and stress-relieving effects of "Shinrin-yoku". J Physiol Anthropol 26(2): 135-142, 2007 http://www.jstage.jst.go.jp/browse/jpa2

[DOI: 10.2114/jpa2.26.135]
\end{abstract}

Keywords: therapeutic effect of forest, natural environment, heart rate variability, salivary cortisol, relaxation

\section{Introduction}

Stress control is one of the most important issues confronting modern society. As reflected by the word "Technostress", coined by Brod in 1984, modern society is becoming more complicated and highly industrialized, consequently causing many stress-related disorders.

In "stressful" daily life, it is a common experience that contact with the natural environment or natural objects provides a feeling of relaxation or a release from tension. A study conducted by Lohr et al. (1996) is considered to give strong support to this contention. They clarified that plants in a windowless office environment contributed to an improvement in worker productivity. The authors have tried to examine the pleasant feelings that natural objects induce in humans by conducting physiological investigations. From studies dealing with the five senses separately, we have clarified that the smell of Japanese cedar wood lowered blood pressure and regional cerebral blood flow in the prefrontal area (Miyazaki et al., 1999), and the sound of murmuring water lowered blood pressure (Mishima et al., 2004). As Frumkin (2001) showed that a deep-seated connection between the natural world and humans was unsurprising from an evolutionary perspective, we assume that human physiological functions have had to adapt to the natural environment; thus, it is somehow a stressor to live in modern "artificial" society. It should be natural for people, having this background, to feel a sense of comfort or affinity with the natural environment.

Frumkin (2001) also pointed out that certain kinds of contact with the natural world could enhance human health. Animals, plants, landscapes, and wilderness experience were cited as components of the natural world that can function to enhance health. As one example of the clinical trials conducted, Urlich (1984) did a remarkable study. He examined 
records on the recovery of patients in a hospital for 10 years and found that patients with tree views had shorter hospitalizations compared to patients with brick-wall views. In the field of environmental health, the natural environment is now seen as one of the factors which have an impact on human health, not in the traditional context of causing harm by exposure to environmental toxins, but from the viewpoint of potentially enhancing our well-being through daily exposure to the natural environment (Frumkin et al., 2002). Through these previous studies, it has been confirmed that the natural environment has a definite beneficial effect on humans.

"Shinrin-yoku" is a word coined by the Forestry Agency of the Japanese government in 1982 to encourage utilization of national forests for enhancement of physical and mental health. It is a compound word made up of two independent words meaning "forest" and "bathing". Like sea bathing, to be in the forest environment and take in the atmosphere of the forest in expectation of a potential curative or therapeutic effect is probably what the word "Shinrin-yoku" intends to convey. Thus, from this perspective, the effect of "Shinrin-yoku" should be considered as non-specific.

Though it would be reasonable to expect that "Shinrinyoku" has beneficial effects on human physiology, there have only been a few studies that have attempted to prove this through on-site experiments. Ohtsuka et al. (1998) found that the mean blood glucose level of diabetic patients significantly decreased after "Shinrin-yoku" (walking $3 \mathrm{~km}$ to $6 \mathrm{~km}$ in the forest). Ohira et al. (1999) examined the immunological and endocrine indices, EEG, and ECG of twenty undergraduates in a forest environment and in a non-forest environment. Their main finding was that NK cell activity and immunoglobulin A, $\mathrm{G}$, and $\mathrm{M}$ were significantly increased after staying 8 hours in a forest environment. There were no significant differences between the forest and non-forest environments in terms of their effects on the other physiological parameters or psychological states (anxiety, mood, and subjective stress). They pointed out the necessity of further studies, adding that the bad weather and low temperature on the day of their experiment might have reduced the pleasantness of "Shinrinyoku".

The previous studies dealt with the effects that occurred over a period of one day. However, in our previous studies, as mentioned before (Miyazaki et al., 1999; Mishima et al., 2004), changes in physiological parameters by the inhalation of wood odor or the sound of murmuring water were observed within 60 to 90 seconds. Though these were the results of laboratory experiments, it can be expected that the impacts of "Shinrin-yoku" on physiological response would be obtained in a shorter time.

The aim of the present study was to clarify the effect of "Shinrin-yoku" as a daily activity on healthy subjects. From the viewpoint of preventive medicine or health maintenance, "Shinrin-yoku" should be accessible and easy to implement. Thus it was our intention to assess a program that included activities of short duration. The evaluation was attempted by measuring various parameters of autonomic nervous activity, the endocrine system, and the immunological system. Subjective feeling was also assessed using a questionnaire. The experiment reported in the present paper was conducted as part of a large-scale ongoing investigation on "Shinrin-yoku" in Japan.

\section{Materials and Methods}

The experiment was conducted in a deciduous broadleaf forest mainly consisting of old-growth beech in Nukumidaira (Oguni, Yamagata, Japan) on the 28th and 29th of July, 2005. For comparison, an area around Niigata Station (Niigata, Japan) was used. The two experimental sites are shown on the map in Figure 1. Hereinafter, the two sites are referred to as the forest area and the city area (Fig. 2). The weather was fine in both areas and the average temperature and relative humidity was $23.5^{\circ} \mathrm{C}$ and $73.4 \%$ in the forest area and $26.4^{\circ} \mathrm{C}$ and $62.1 \%$ in the city area, respectively.

The subjects were 12 male university students aged from 21 to 23 (mean \pm SD: $22.0 \pm 1.0$ ). The subjects were assembled in the afternoon on the day before the experiment. Sufficient information on the aim and process of the experiment was provided and written informed consent was obtained. The study was performed under the regulations of the Institutional Review Committee of the Forest and Forest Products Research Institute of Japan. After a brief orientation, the subjects previewed the experimental sites in the forest and the city areas. Then a measurement practice was conducted at a place of accommodation, which was located at approximately the same distance (about 60 minutes by car) from both

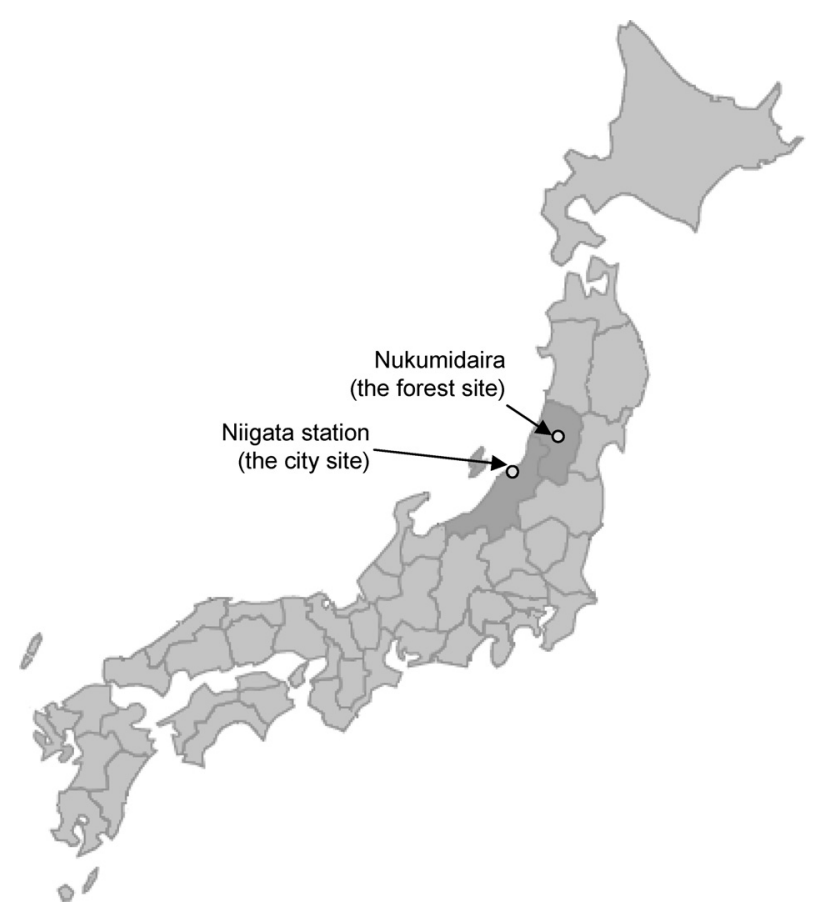

Fig. 1 Location of the experimental sites. 

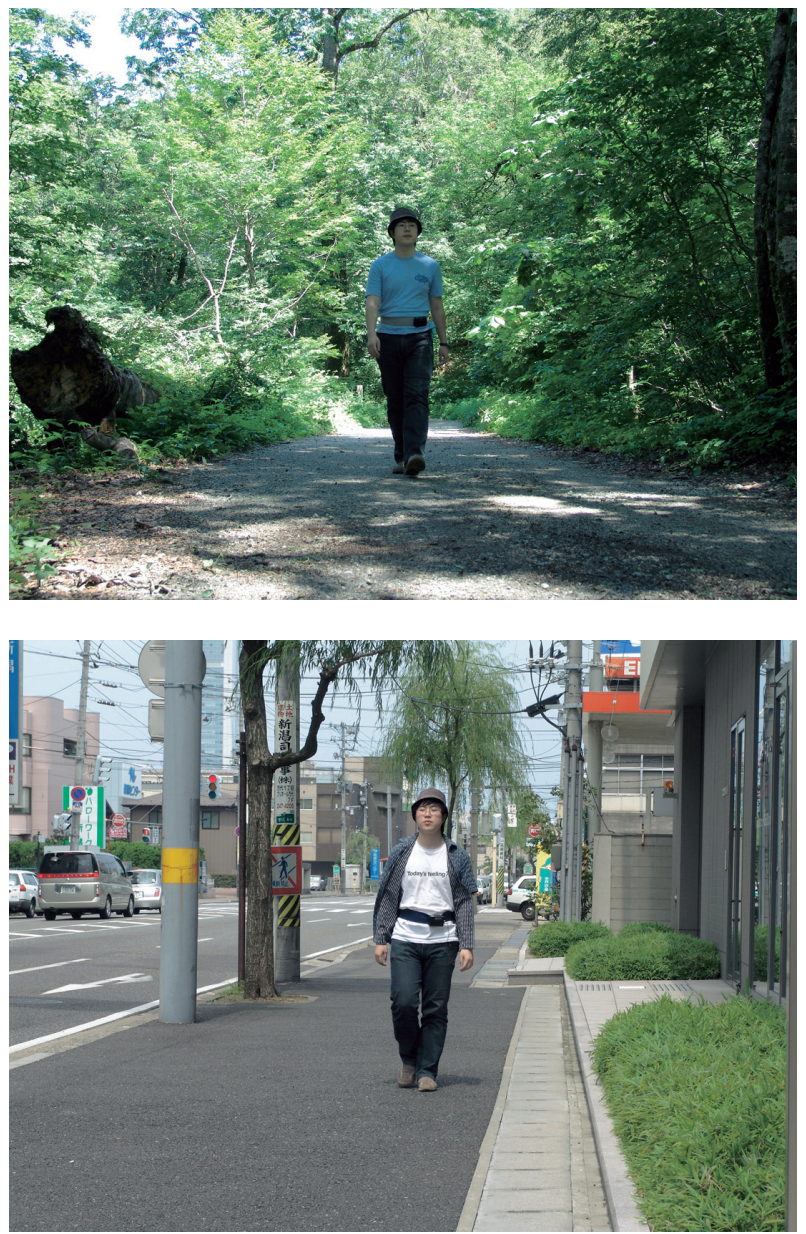

Fig. 2 The scenery in the two experimental sites. upper: Forest area lower: City area.

experimental sites. Each subject stayed in a single room in the hotel and all subjects had the same meals until the end of the experiment.

The subjects were divided randomly into two groups consisting of six people each. On the first day of the experiment, one group was sent to the forest area, and the other was sent to the city area. On the second day, each group went to the other area to eliminate the order effect.

In the morning, each group was taken to the experimental site and rested for a while in a nearby resting room. In the forenoon, the subjects walked a predetermined course in each area at an unhurried pace for 15 minutes. In the afternoon, after taking lunch in the resting room, they sat on chairs watching the scenery in each area for 15 minutes. The subjects engaged in the walking and watching individually.

Physiological measurements were conducted six times a day: (i) in the morning at the place of accommodation before breakfast (06:15-07:15); (ii) before walking (10:40-11:30); (iii) after walking (11:00-11:50); (iv) before watching (14:1015:00); (v) after watching (14:30-15:20); (vi) in the evening at the place of accommodation before dinner (18:00-19:00). The $\mathrm{R}-\mathrm{R}$ interval was measured continuously during the walking and watching in addition to these six specific measurement times.

The measured physiological parameters were the R-R interval of the electrocardiogram to analyze heart rate variability (HRV), systolic and diastolic blood pressure, pulse rate, salivary cortisol concentration, and secretory immunoglobulin A (s-IgA) concentration in saliva. R-R intervals were obtained by an ambulatory electrocardiogram monitor (Active Tracer AC301A, GMS Corporation). They were measured over 2 minutes during the resting state with eyes closed in the morning and the evening, and before and after walking and watching. R-R intervals were also taken continuously for 15 minutes during walking and watching. Systolic and diastolic blood pressure, and pulse rate were measured by a digital blood pressure monitor using oscillometric methods (HEM1000, Omron) on the right upper arm. Saliva for analysis of cortisol and s-IgA was collected using Salivette devices over a two-minute period. The saliva samples were frozen after collection and subsequently analyzed by SRL, Inc. In addition to the physiological measurements, subjective "comfortable-uncomfortable" and "calm-roused" feelings were estimated using a 13-point scale. "Refreshed" feeling was measured with the Stress-Refresh feeling test (Mackay et al., 1978). These subjective tests using the questionnaire were also carried out six times a day at the time of the physiological measurements.

$\mathrm{R}-\mathrm{R}$ interval data were analyzed by the maximum entropy method (Memcalc, GMS, Ohtomo et al., 1994). The power of the low-frequency (LF; $0.04-0.15 \mathrm{~Hz}$ ) component and the high-frequency $(\mathrm{HF} ; 0.15-0.4 \mathrm{~Hz}$ ) component of the obtained heart rate power spectrum were calculated for each minute. It is considered that $\mathrm{HF}$ reflects parasympathetic nervous activity and $\mathrm{LF} /(\mathrm{LF}+\mathrm{HF})$ reflects sympathetic nervous activity. A paired $t$-test was used to compare the physiological data between the forest area and the city area. The Wilcoxon signed rank test was used to compare the data on subjective feelings. All statistical analysis was performed using StatView version 5.0 (SAS Institute Inc). $p<0.05$ was considered to be significant.

\section{Results}

Subjective "comfortable" feelings in the forest area and the city area at each measurement time are shown in Figure 3. The forest area was evaluated as producing significantly more comfortable feelings before and after walking $(p<0.05)$ and after being seated and watching $(p<0.01)$ than the city area did. By comparing before and after watching, it was clarified that watching scenery in the forest area significantly increased feelings of comfort $(p<0.05)$ while activities in the city area significantly decreased feelings of comfort $(p<0.05$ when walking, $p<0.01$ when watching). Figure 4 shows the results for a "calm" feeling in the forest and city areas. The forest area was rated as producing significantly calmer feelings after walking and watching than the city area did $(p<0.05, p<0.01$, 


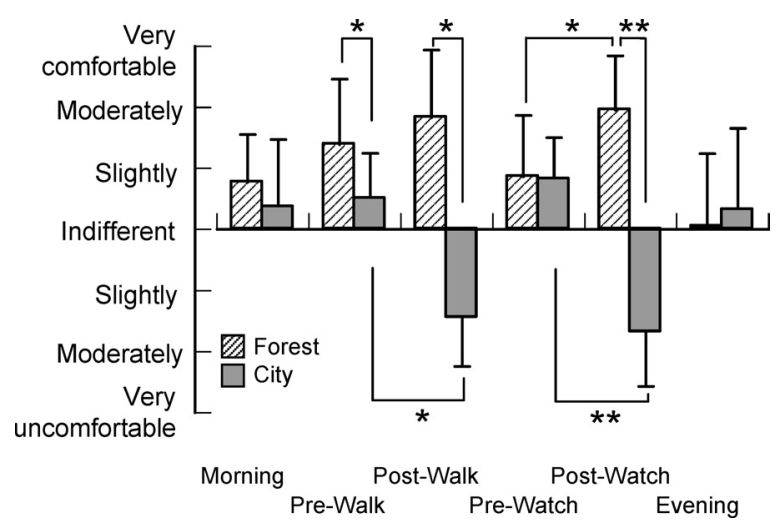

Fig. 3 Subjective comfortable feeling measured by questionnaire at six measurement times in the forest area and in the city area.

$N=9$ at "Before walking" and "After walking", $N=11$ at the other times. *: $p<0.05,{ }^{* *}: p<0.01$ by Wilcoxon signed rank test.

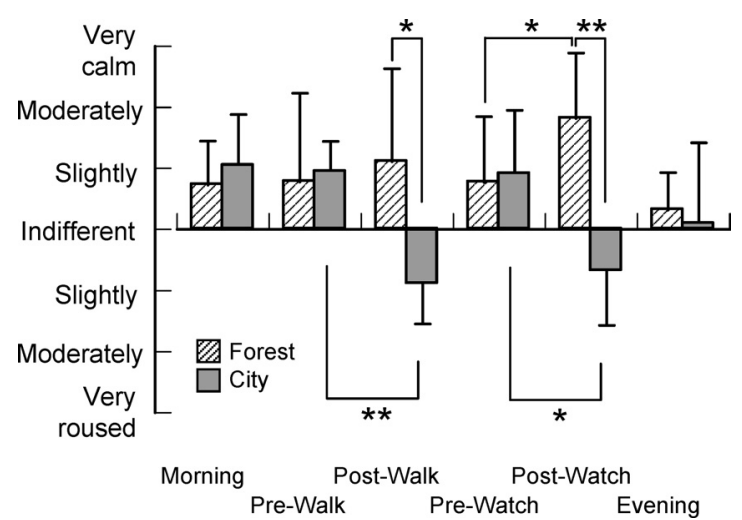

Fig. 4 Subjective calm feeling measured by questionnaire at six measurement times in the forest area and in the city area.

$N=9$ at "Before walking" and "After walking", $N=11$ at the other times. *: $p<0.05, * *: p<0.01$ by Wilcoxon signed rank test.

respectively). As in the case of a "comfortable" feeling, watching in the forest area significantly enhanced the feeling of calm $(p<0.05)$, whereas the activities in the city environment lowered this feeling $(p<0.01$ when walking, $p<0.05$ when watching). Figure 5 shows the scores for a "refreshed" feeling as gauged by the Stress-Refresh test. The score was significantly higher in the forest area than in the city area before and after walking and before and after watching $(p<0.05$ before and after walking, and before watching, $p<0.01$ after watching). Significant differences between before and after the activities were only observed for the city area, i.e., the city area caused a significant decrease in feeling refreshed $(p<0.05)$.

Figure 6 shows the mean value of systolic blood pressure in each experimental site at each measurement time. Systolic blood pressure was significantly lower in the forest area before walking $(p<0.05)$ and before $(p<0.01)$ and after $(p<0.05)$ watching than in the city area. Figure 7 shows diastolic blood pressure in the same sequence as systolic blood pressure. Diastolic blood pressures showed significantly lower values in

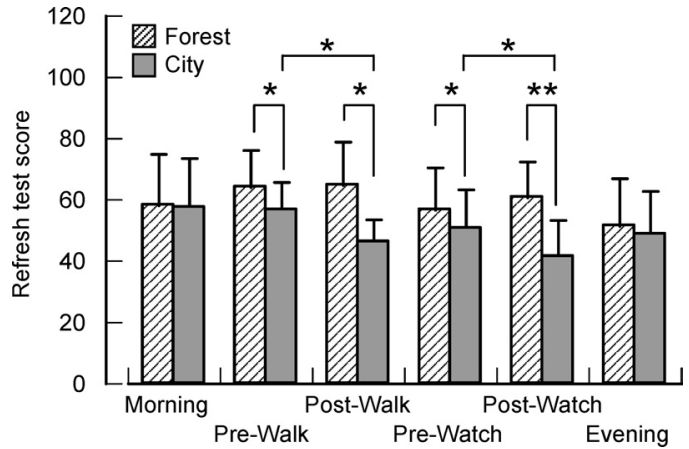

Fig. 5 Subjective refreshed feeling measured by the Stress-Refresh feeling test at six measurement times in the forest area and in the city area.

$N=9$ at "Before walking" and "After walking", $N=11$ at the other times. *: $p<0.05, * *: p<0.01$ by Wilcoxon signed rank test.

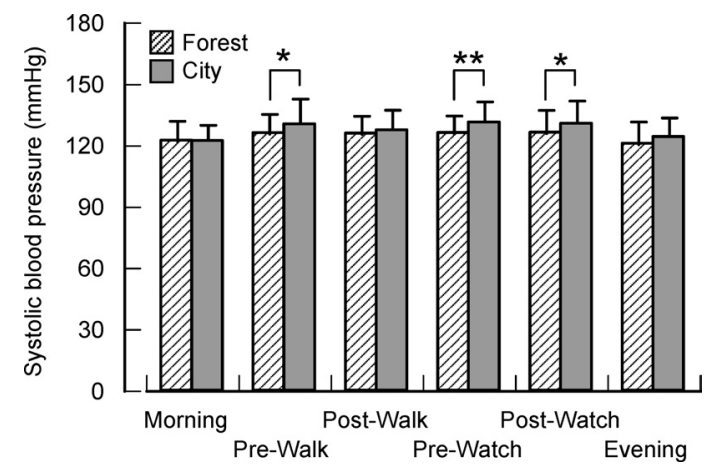

Fig. 6 Changes in systolic blood pressure determined at six measurement times in the forest area and in the city area.

$N=9$ at "Before walking" and "After walking", $N=11$ at the other times. *: $p<0.05,{ }^{* *}: p<0.01$ by paired $t$-test.

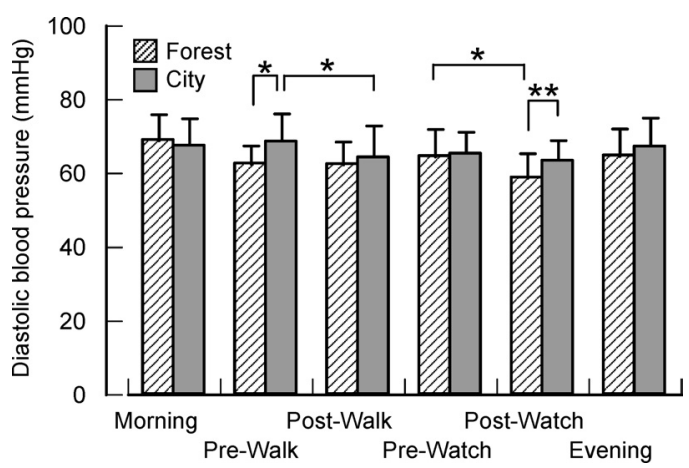

Fig. 7 Changes in diastolic blood pressure determined at six measurement times in the forest area and in the city area. $N=9$ at "Before walking" and "After walking", $N=11$ at the other times. *: $p<0.05, * *: p<0.01$ by paired $t$-test.

the forest area before walking $(p<0.05)$ and after watching $(p<0.01)$. In a comparison between before and after, diastolic blood pressure decreased following walking in the city area $(p<0.05)$ and watching scenery in the forest area $(p<0.05)$. Figure 8 shows the change in the pulse rate. There was an overall tendency for the pulse rate to be lower in the forest area 
than in the city area except in the morning, and a significant difference between the two sites was observed before walking. Though it did not reach a significant level, the $p$-value was less than 0.06 after walking and in the evening. Pulse rate significantly decreased as a result of watching scenery in the city area $(p<0.01)$.

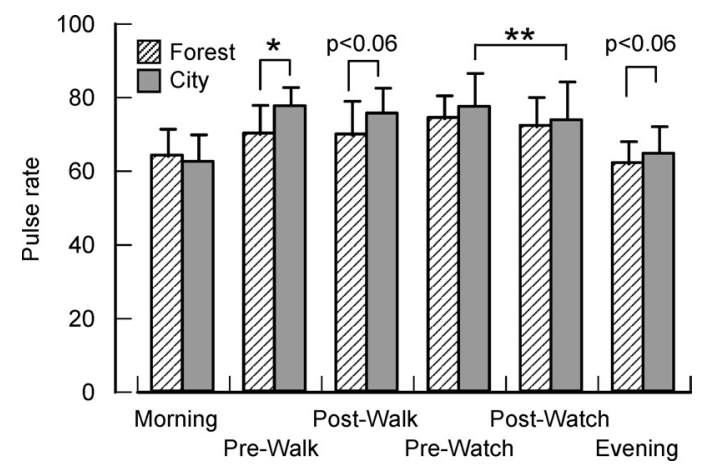

Fig. 8 Changes in pulse determined at six measurement times in the forest area and in the city area.

$N=9$ at "Before walking" and "After walking", $N=11$ at the other times. $*: p<0.05, * *: p<0.01$ by paired $t$-test.
To assess the activity in the autonomic nervous system separately from sympathetic nervous activity and parasympathetic nervous activity, we investigated HRV by means of frequency analysis of the R-R interval. Figure 9 shows the minute-by-minute change in the power of the HF component of HRV over time. The data sequence is as follows: morning (at the place of accommodation), before, during and after walking, before, during and after watching, and evening (at the place of accommodation). The HF power tended to be higher in the forest area overall during walking. A significant difference between the forest area and the city area was observed at the 1 st $(p<0.01)$, 9th $(p<0.05)$, and 15 th $(p<0.05)$ minute during watching. Though the HF power tended to be higher in the forest area than in the city area before and after walking and watching, it did not reach a significant difference ( $p$-value was less than 0.06 at the 1 st minute in the measurement before walking and at the 2 nd minute after watching). Figure 10 shows the variation in $\mathrm{LF} /(\mathrm{LF}+\mathrm{HF})$ over time. The value in the forest area was significantly lower at the 2nd $(p<0.05)$ and 11 th $(p<0.05)$ minute during walking and the 1 st $(p<0.05)$ and 9 th $(p<0.05)$ minute during watching.

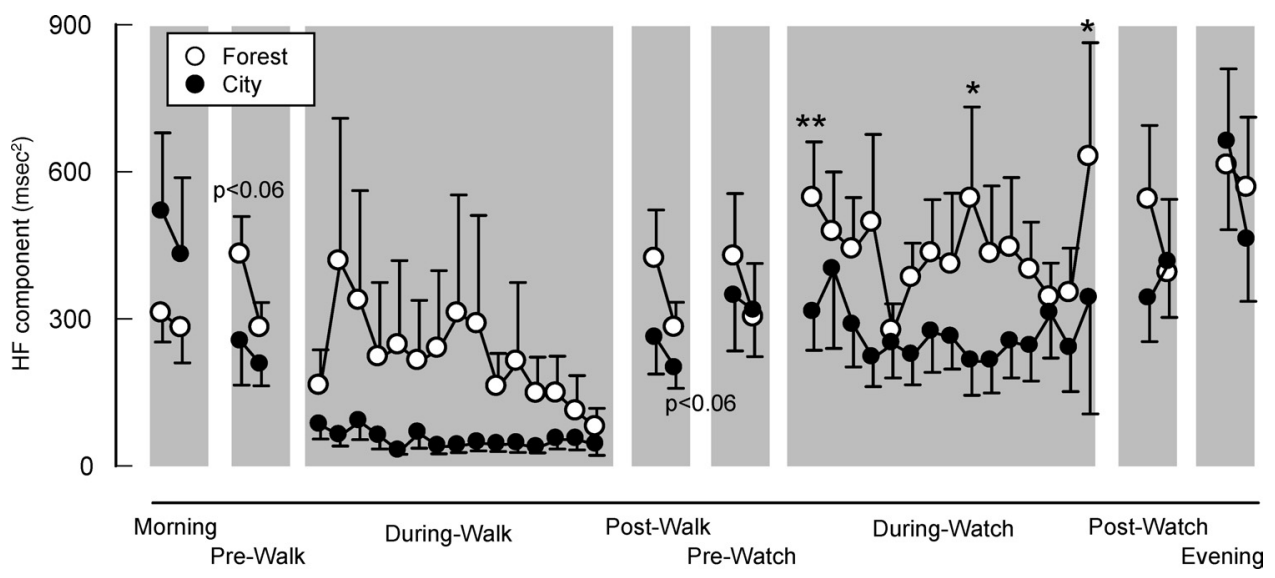

Fig. 9 Time-series change in the power of the HF component of HRV in the forest area and in the city area. $N=5-12, *: p<0.05, * *: p<0.01$ by paired $t$-test.
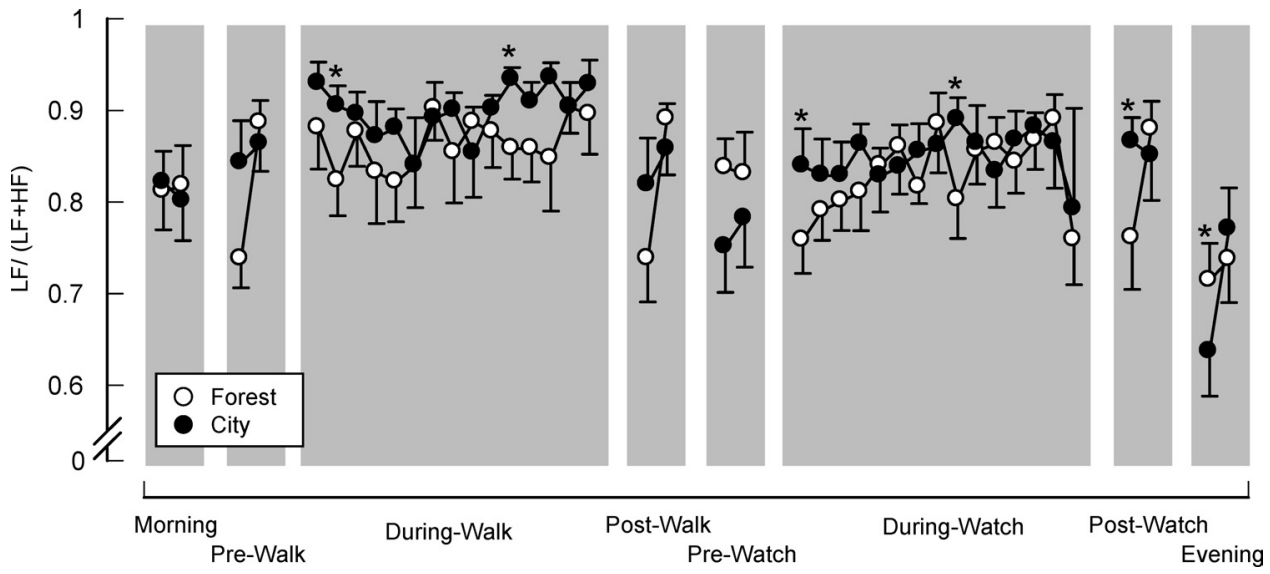

Fig. 10 Time-series change in $\mathrm{LF} /(\mathrm{LF}+\mathrm{HF})$ of $\mathrm{HRV}$ in the forest area and in the city area. $N=5-12, *: p<0.05$ by paired $t$-test. 
Figure 11 shows the time course change in the salivary cortisol concentration. As was already known, diurnal variations where concentration is high in the morning and tends to decrease as time progresses were observed in both areas. Cortisol concentration was lower in the forest area than in the city area at all measurement times, and there was a significant difference between the two sites before and after walking, and after watching $(p<0.05)$. The $p$-value was less than 0.06 before watching. The present study found no significant difference in the s-IgA concentration. No significant diurnal variation was found in the s-IgA concentration.

\section{Discussion}

The results for the forest area and the city area are summarized in Table 1. No indices showed significant differences between the forest area and the city area for the measurements taken in the morning and the evening. The

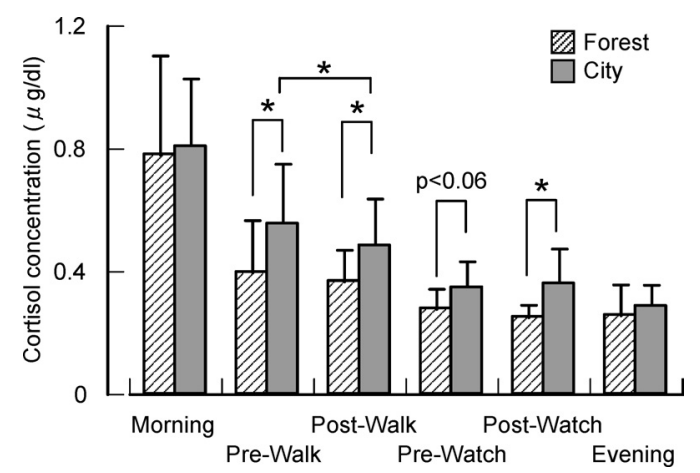

Fig. 11 Changes in salivary cortisol concentration at six measurement times in the forest area and in the city area.

$N=9$ at "Before walking" and "After walking", $N=11$ at the other times. *: $p<0.05$ by paired $t$-test. differences were mainly observed before walking and after being seated and watching the scenery, followed by after walking, then before watching. All of the indices except s-IgA were generally in excellent agreement with each other.

The results for the subjective evaluations showed that walking around or watching the scenery in the forest area created a feeling of comfort and calm. Feeling refreshed was higher in the forest area both when walking and watching, and both before and after the activities, which can be interpreted as indicating that the forest environment itself induced the refreshed feeling regardless of the kind of activity and the measurement time.

The findings for blood pressure and pulse rate demonstrated that activities in the forest area caused a relaxed physiological state compared to the city area. The significant differences in all of the three parameters (systolic and diastolic blood pressure, and pulse rate) before walking suggest that the two environments had already had different impacts on physiology before activities commenced. The temperature in the period 10:00-12:00 was lower in the forest area (about $22-24^{\circ} \mathrm{C}$ in the forest and $26-27^{\circ} \mathrm{C}$ in the city), and the forest area was felt as significantly more "comfortable" and "refreshing" before walking. The whole environment in the forest area was considered to induce lower blood pressure and pulse rate. This might also be affected by the fact that the subjects had stayed in the forest environment for 1.5-2.5 hours from 9:00, which corresponded to the measurement time of "before walking". The reason for no significant differences after walking seemed to be that blood pressure and pulse rate tended to decrease (a significant decrease in diastolic blood pressure) after walking in the city area whereas they were rather stable in the forest area. Since pulse rate did not increase, the 15-minute walking conducted in the present study was assumed to be light exercise for these subjects. It has been reported that moderate

Table 1 Summary of the comparison between the forest and city areas.

\begin{tabular}{|c|c|c|c|c|c|c|c|c|c|c|}
\hline & \multicolumn{7}{|c|}{ Physiological responses } & \multirow{2}{*}{\multicolumn{3}{|c|}{ Subjective feelings }} \\
\hline & \multicolumn{5}{|c|}{ Autonomic nervous system } & \multirow{2}{*}{$\begin{array}{c}\text { Endocrine } \\
\text { system }\end{array}$} & \multirow{2}{*}{$\begin{array}{c}\begin{array}{c}\text { Immune } \\
\text { system }\end{array} \\
\text { s-IgA }\end{array}$} & & & \\
\hline & $\begin{array}{l}\text { Sys } \\
\text { BP }\end{array}$ & $\begin{array}{l}\text { Dias } \\
\text { BP }\end{array}$ & $\begin{array}{l}\text { Pulse } \\
\text { Rate }\end{array}$ & $\mathrm{HF}$ & $\begin{array}{c}\mathrm{LF} / \\
(\mathrm{LF}+\mathrm{HF})\end{array}$ & & & Comfort & Calm & Refreshed \\
\hline \multicolumn{11}{|l|}{ Morning } \\
\hline Pre-walk & $\mathrm{F}<\mathrm{C}^{*}$ & $\mathrm{~F}<\mathrm{C}^{*}$ & $\mathrm{~F}<\mathrm{C}^{*}$ & & $\mathrm{~F}<\mathrm{C}^{*}$ & $\mathrm{~F}<\mathrm{C}^{*}$ & & $\mathrm{~F}>\mathrm{C}^{*}$ & & $\mathrm{~F}>\mathrm{C}^{*}$ \\
\hline Post- walk & & & & & walk & $\mathrm{F}<\mathrm{C}^{*}$ & & $\mathrm{~F}>\mathrm{C}^{*}$ & $\mathrm{~F}>\mathrm{C}^{*}$ & $\mathrm{~F}>\mathrm{C}^{*}$ \\
\hline Pre-watch & $\mathrm{F}<\mathrm{C}^{* *}$ & & & \multirow{2}{*}{$\begin{array}{l}\mathrm{F}>\mathrm{C}^{*} \\
\text { during } \\
\text { watch }\end{array}$} & \multirow{2}{*}{$\begin{array}{l}\mathrm{F}<\mathrm{C}^{*} \\
\text { during } \\
\text { watch }\end{array}$} & & & & & $\mathrm{F}>\mathrm{C}^{*}$ \\
\hline Post-watch & $\mathrm{F}<\mathrm{C}^{*}$ & $\mathrm{~F}<\mathrm{C}^{* *}$ & & & & $\mathrm{~F}<\mathrm{C}^{*}$ & & $\mathrm{~F}>\mathrm{C}^{* *}$ & $\mathrm{~F}>\mathrm{C}^{*}$ & $\mathrm{~F}>\mathrm{C}^{* *}$ \\
\hline Evening & & & & & & & & & & \\
\hline
\end{tabular}

F: Forest area, C: City area, * indicates that significant differences were observed in the index at the $5 \%$ significance level, $* *$ indicates that significant differences were observed in the index at the $1 \%$ significance level. 
exercise decreases blood pressure compared to the level before exercise (Halliwill, 2001). The significant decrease in diastolic blood pressure in the city area was hence considered to be the effect of exercise. We assumed that diastolic blood pressure was lowered already at the measurement time of "before walking" in the forest area, so it did not decrease as a result of walking. The significantly lower blood pressure after being seated and watching the scenery in the forest area showed that the activity had the effect of reducing stress. The fact that the pulse rate of the subjects who returned from the forest in the evening tended to be lower $(p<0.06)$ might indicate that the effect of "Shinrin-yoku" lasted for a certain amount of time.

The results for HRV showed that parasympathetic nervous activity tended to be dominant in the forest area, which implies that "Shinrin-yoku" had a relaxing effect. A rapid decrease in HF when doing submaximal exercise (Yamamoto et al., 1991) or ergometer exercise until exhaustion (Tabusadani et al., 2001) has been reported in previous studies, but the decrease in HF during walking in the city area in the present study was not considered to be caused only by the exercise, since the quantity of physical activity during walking calculated from the acceleration of the subject was at the same level in each area, and pulse rate did not show an increase after walking (the exercise load was not as high as in previous studies). Thus the decrease in $\mathrm{HF}$ components in the city area was also considered to relate to the perceived mental stress (Dishman et al., 2000; Hjortskov et al., 2004). From this point of view, the relatively high $\mathrm{HF}$ in the forest area indicated a connection with the subjective "comfortable" and "calm" feelings. Recently, it was reported that soothing music caused a higher HF component than stimulating music did (Iwanaga et al., 2005), and that an increase in HF power was observed during Zen meditation (Murata et al., 2004). The outcomes in the present study are supportive of the results from those previous studies. The effect of the environment was more significant during watching. As the subjects sat still in a chair in both areas, the results during watching can be inferred to have a close association with the mood state. Parasympathetic nervous activity was more dominant than in the period of walking in both areas, and moreover, it was significantly more dominant in the forest area than in the city area. The standard deviation of HF power was larger in the forest area, possibly because walking around or watching scenery in the city area caused a stressed, heightened state equally in all subjects, whereas the relaxing and calming effect of "Shinrin-yoku" was more variable and depended to a certain extent on the individual. Rosenwinkel et al. (2001) pointed out that HRV may be more applicable to assessing parasympathetic nervous activity than for assessing sympathetic function. In the present study, the difference between the forest and city areas was not as clear in $\mathrm{LF} /(\mathrm{LF}+\mathrm{HF})$, but it can be supposed that sympathetic nervous activity was more dominant in the city area during walking and watching.

From the investigations of many previous studies (Kirschbaum and Hellhammer, 1989; Ockenfels et al., 1995), the result that cortisol concentration was significantly lower in the forest area before and after walking, and after watching can be interpreted as clearly demonstrating the relaxation effect of "Shinrin-yoku". O'Connor and Corrigan (1987) reported that a significant increase in salivary cortisol was elicited by submaximal exercise, while Jin (1989) found that moderate exercise (practice of Tai Chi) decreased salivary cortisol levels. The significant decrease after walking in the city area in the present study might be attributable to the effect of the exercise. The reason why there was no significant tendency toward an increase or decrease in the $\operatorname{IgA}$ concentration in saliva in the present study is unclear, and further consideration from the viewpoint of individual variation, e.g., a connection with personality (Ohira et al., 1999), or a relationship between kinds of stress and the stress reaction mechanism (Fujiwara and Yokoyama, 1990) is needed.

The responses in the parameter reflecting autonomic nervous activity and cortisol concentration obviously demonstrated that "Shinrin-yoku" in the forest was perceived as a relaxing stimulation and caused an opposite response to stress reaction through both the hypothalamus-pituitaryadrenal cortex axis and the hypothalamus-sympathetic nervous system-adrenal medulla axis. This idea is also supported by the excellent agreement between the physiological responses and the subjective ratings. It is considered that these results were induced not by specific components in the forest, but by the whole environment, including air, scenery, smell, sound, and climatic conditions such as temperature.

In summary, in the forest area, 1) blood pressure and pulse rate were significantly lower, and 2) the power of the $\mathrm{HF}$ component tended to be higher and $\mathrm{LF} /(\mathrm{LF}+\mathrm{HF})$ tended to be lower. Also, 3) salivary cortisol concentration was significantly lower in the forest area. The physiological responses suggest that sympathetic nervous activity was suppressed and parasympathetic nervous activity was enhanced in the forest area, and "Shinrin-yoku" was responsible for reducing the stress. In the subjective evaluation, 4) "comfortable", "calm", and "refreshed" feelings were significantly higher in the forest area. The relaxing effect of "Shinrin-yoku" was also felt subjectively. In conclusion, the present study has proved the relaxing and stress-relieving effects of "Shinrin-yoku" by means of a physiological investigation, with subjective evaluations providing supporting evidence.

Acknowledgements This study was supported partly by Research Project for Utilizing Advanced Technologies in Agriculture, Forestry and Fisheries, 2004 (1603) from the Ministry of Agriculture, Forestry and Fisheries, Forest Therapeutic Effects Research Association, Grants-in-Aid for Scientific Research (No. 16107007) from the Ministry of Education, Culture, Sports, Science and Technology.

\section{References}

Brod C (ed) (1984) Techno Stress: The Human Cost of the 
Computer Revolution. Addison-Wesley, Boston

Dishman RK, Nakamura Y, Garcia ME, Thompson RW, Dunn AL, Blair SN (2000) Heart rate variability, trait anxiety, and perceived stress among physically fit men and women. Int J Psychophysiol 37(2): 121-133

Frumkin H (2001) Beyond toxicity: human health and the natural environment. Am J Prev Med 20(3): 234-240

Frumkin H, Jackson RJ, Coussens CM (eds) (2002) Health and the Environment in the Southeastern United States. The National Academies Press, Washington, D.C

Fujiwara R, Yokoyama M (1990) Stress and immunological response. Igaku no Ayumi 154(5-6) [In Japanese]

Halliwill JR (2001) Mechanisms and clinical implications of post-exercise hypotension in humans. Exerc Sport Sci Rev 29(2): 65-70

Hjortskov N, Rissen D, Blangsted AK, Fallentin N, Lundberg U, Sogaard K (2004) The effect of mental stress on heart rate variability and blood pressure during computer work. Eur J Appl Physiol 92(1-2): 84-89

Iwanaga M, Kobayashi A, Kawasaki C (2005) Heart rate variability with repetitive exposure to music. Biol Psychol 70(1): 61-66

Jin P (1989) Changes in heart rate, noradrenaline, cortisol and mood during Tai Chi. J Psychosom Res 33(2): 197-206

Kirschbaum C, Hellhammer DH (1989) Salivary cortisol in psychobiological research: an overview. Neuropsychobiology 22(3): 150-169

Lohr VI, Pearson-Mims CH, Goodwin GK (1996) Interior plants may improve worker productivity and reduce stress in a windowless environment. J environ hortic 14(2): 97-100

Macay C, Cox T, Buroows G, Lazzerini T (1978) An inventory for the measurement of self-reported stress and arousal. Br J Soc Clin Psychol 17: 283-284

Mishima R, Kudo T, Tsunetsugu Y, Miyazaki Y, Yamamura C, Yamada Y (2004) Effects of sounds generated by a dental turbine and a stream on regional cerebral blood flow and cardiovascular responses. Odontology 92(1): 54-60

Miyazaki Y, Morikawa T, Yamamoto N (1999) Effect of wooden odoriferous substances on humans. Appl Human Sci 18(5): 189

Murata T, Takahashi T, Hamada T, Omori M, Kosaka H, Yoshida H, Wada Y (2004) Individual trait anxiety levels characterizing the properties of Zen meditation. Neuropsychobiology 50(2): 189-194

Ockenfels MC, Porter L, Smyth J, Kirschbaum C, Hellhammer DH, Stone AA (1995) Effect of chronic stress associated with unemployment on salivary cortisol: overall cortisol levels, diurnal rhythm, and acute stress reactivity. Psychosom Med 57(5): 460-467

O'Connor PJ, Corrigan DL (1987) Influence of short-term cycling on salivary cortisol levels. Med Sci Sports Exerc 19(3): 224-228

Ohira H, Watanabe Y, Kobayashi K, Kawai M (1999) The type A behavior pattern and immune reactivity to brief stress: change of volume of secretory immunoglobulin A in saliva. Percept Mot Skills 89(2): 423-430

Ohira H, Takagi S, Mauis K, Oishi M, Obata A (1999) Effects of shinrin-yoku (forest-air bathing and walking) on mental and physical health. Tokai Women's University Kiyou 19: 217-232 [In Japanese]

Ohtomo N, Terachi S, Tanaka Y, Tokiwano K, Kaneko N (1994) New method of time series analysis and its application to Wolf's sunspot number data. Jpn J Appl Phys 33: $2821-2831$

Ohtsuka Y, Yabunaka N, Takayama S (1998) Shinrin-yoku (forest-air bathing and walking) effectively decreases blood glucose levels in diabetic patients. Int J Biometeorol 41(3): $125-127$

Rosenwinkel ET, Bloomfield DM, Arwady MA, Goldsmith RL (2001) Exercise and autonomic function in health and cardiovascular disease. Cardiol Clin 19(3): 369-387

Tabusadani M, Hayashi Y, Sekikawa K, Kawaguchi K, Onari K, Kobayashi K (2001) Relationship between heart rate variability during execise and ventilatory thresholdAssessment by MemCalc system-(first report). Jpn J Phys Fitness Sports Med 50: 185-192 [In Japanese]

Ulrich RS (1984) View through a window may influence recovery from surgery. Science 27; 224(4647): 420-421

Yamamoto Y, Hughson RL, Peterson JC (1991) Autonomic control of heart rate during exercise studied by heart rate variability spectral analysis. J Appl Physiol 71(3): 11361142

This article was presented at the 8th International Congress of Physiological Anthropology, 2006 (ICPA 2006), in Kamakura, Japan.

Received: September 30, 2006

Accepted: December 22, 2006

Correspondence to: Yuko Tsunetsugu, 1 Matsunosato, Tsukuba, Ibaraki 305-8687, Japan

Phone: +83-29-829-8310

Fax: +83-29-874-3720

e-mail: yukot@ffpri.affrc.go.jp 